\title{
Meta-Analisis media scratch terhadap keterampilan computational thinking siswa SMA dalam pembelajaran fisika
}

\author{
Widya Nugraheni Widiningrum \\ Pendidikan Fisika, Universitas Negeri Semarang, Indonesia \\ Surat-e: widyanugraheni@students.unnes.ac.id
}

\section{Wahyu Hardyanto}

Pendidikan Fisika, Universitas Negeri Semarang, Indonesia Surat-e: hardy@mail.unnes.ac.id

\section{Siti Wahyuni}

Pendidikan Fisika, Universitas Negeri Semarang, Indonesia Surat-e: wahyuni.smg@mail.unnes.id

\section{Putut Marwoto}

Pendidikan Fisika, Universitas Negeri Semarang, Indonesia Surat-e: pmarwoto@mail.unnes.ac.id

\section{Budi Naini Mindyarto}

Pendidikan Fisika, Universitas Negeri Semarang, Indonesia Surat-e: budinaini@mail.unnes.ac.id

\begin{abstract}
Abstrak. Pembelajaran jarak jauh membuat siswa kesulitan dalam belajar fisika yang abstrak sehingga diperlukan media yang menarik minat belajar siswa. Scratch merupakan salah satu media yang mendukung dalam pelaksanaan pembelajaran tersebut. Tujuan penelitian ini adalah mengetahui kelebihan dan kekurangan serta keterampilan computational thinking selama menggunakan media pembelajaran scratch pada fisika jenjang SMA. Metode yang digunakan adalah Systematic Literature Review dengan analisis deskriptif kualitatif. Scratch mampu meningkatkan keterampilan computational thinking siswa karena didesain untuk mengembangkan kreatifitas dengan membuat animasi dan simulasi, kemampuan berpikir secara sistematis, kolaboratif dan dapat merealisasikan algoritma sehingga mampu menerapkan pola pikir logika yang dapat membuat konsep sederhana menjadi kompleks dalam pembelajaran fisika.
\end{abstract}

Kata kunci: metaanalisis fisika, scratch, computational thinking

\begin{abstract}
Distance education makes it difficult for students to learn abstract physics that is needed media that attracts students interesting. Scratch is one of the media that supports the implementation of this learning. The research aims to determine strengths and weaknesses, computational thinking skills while using media scratch in high school physics. The method used is a systematic literature review with qualitative descriptive analysis. Scratch can improve computational thinking skills because it develops creativity, think systematically, collaboratively, and realize algorithms made up apply logical thinking patterns that can make simple concepts complex in physics learning.
\end{abstract}

Keywords: physics meta-analysis, scratch, computational thinking.

\section{Pendahuluan}

Pandemi Coronavirus disease (covid-19) telah mengubah tatanan dunia terutama di bidang pendidikan. Perubahan tersebut terletak pada pelaksanaan pembelajaran di sekolah yaitu tidak adanya pembelajaran secara luring atau penutupan sementara lembaga pendidikan dalam upaya mencegah penyebaran covid-19. UNESCO 
menyebutkan bahwa pandemi covid-19 menyebabkan lebih dari 1,5 miliar siswa di seluruh dunia merasakan dampak akibat penutupan sekolah dan universitas [1]. Berdasarkan data UNESCO tanggal 19 Maret 2020, 112 negara telah menerapkan kebijakan belajar dari rumah, antara lain Malaysia, Thailand, Jerman, Austria, Meksiko, Afrika Selatan, Yaman, dan Zambia. Dari 112 negara tersebut, 101 negara menerapkan kebijakan belajar dari rumah secara nasional. Sementara 11 negara lainnya, termasuk Indonesia, menerapkan belajar di rumah di wilayah-wilayah tertentu [2]. Proses pembelajaran secara daring atau belajar dari rumah melalui pendidikan jarak jauh merupakan salah satu solusi yang dalam pelaksanaannya belum optimal secara keseluruhan [2]-[6].

Pada prosesnya, pembelajaran jarak jauh memisahkan antara guru dan siswa dengan bantuan sumber belajar yaitu teknologi informasi dan komunikasi atau menggunakan media lainnya. Pembelajaran jarak jauh sering dikaitkan dengan pembelajaran mandiri, sehingga membuat siswa kesulitan dalam belajar. Salah satu mata pelajaran yang dianggap sulit adalah fisika. Siswa menganggap belajar fisika secara luring sulit untuk dipahami apalagi selama masa pembelajaran jarak jauh [7]. Fisika merupakan pembelajaran yang membutuhkan pembuktian dan pemahaman fisik (eksperimen) [8]. Proses untuk membuktikan suatu teori yaitu membuat media pembelajaran dengan menggunakan komputer. Hal ini didukung oleh penelitian yang menyatakan bahwa Computer Assisted Instruction lebih efektif daripada pengajaran tradisional dalam pencapaian siswa dalam bidang fisika [9]. Keunggulan komputer dalam menyimpan dan mengolah data serta membuat animasi mampu membuat tampilan yang berbeda dalam pembelajaran sehingga dapat menarik minat belajar siswa [10].

Mengawali penelitian ini, peneliti telah mewawancarai 15 orang guru SMA/MA/SMK di wilayah Semarang, Ungaran, Kendal, Pekalongan, Tegal dan Kudus untuk mendapatkan gambaran mengenai pembelajaran jarak jauh. Hasil wawancara menunjukkan bahwa 93\% guru fisika tidak pernah melaksanakan eksperimen selama pembelajaran jarak jauh, sedangkan $7 \%$ guru sering melakukan eksperimen saat pembelajaran jarak jauh. Hal tersebut dikarenakan sulitnya penggunaan media eksperimen yang digunakan selama pembelajaran di rumah sehingga guru hanya memberikan penugasan selama masa pembelajaran jarak jauh. Oleh sebab itu, diperlukannya suatu media pembelajaran yang mudah dan praktis sehingga mampu membantu siswa dalam bereksperimen pada materi fisika yang abstrak.

Media pembelajaran yang mampu mendukung dalam eksperimen fisika jarak jauh yaitu memiliki kriteria sebagai media interaktif. Media tersebut diharapkan dapat digunakan oleh siswa dalam bereksperimen secara aktif dan mendapatkan umpan balik berupa pemahaman konsep pada materi. Salah satu media pembelajaran yang mampu membantu siswa belajar pada konsep yang abstrak adalah Scratch [11], [12]. Pemrograman scratch berbentuk seperti puzzle sehingga memudahkan siswa dalam mempelajari abstraksi konsep dari yang sederhana menjadi kompleks, selain itu scratch dapat diakses secara online maupun offline. Namun, diperlukan program tambahan pada scratch offline berupa program database dan web server [12]. Disamping itu, media pembelajaran scratch mampu meningkatkan hasil belajar siswa yang ditujukan pada keterampilanketerampilan yang terukur karena menerapkan pola pikir logika yang mampu mengabstraksi masalah dengan cara menyusun program sederhana menjadi kompleks [13].

Berdasarkan paparan tersebut, tujuan penelitian ini dilakukan guna mengkaji media scratch terhadap keterampilan computational thinking siswa dengan memetakan hasil riset dari penelitian terdahulu pada pembelajaran fisika jenjang SMA untuk mengetahui cakupan media scratch serta ranah keterampilan yang cukup luas. Maka dari itu penelitian ini berjudul "Meta-Analisis Media Scratch terhadap Keterampilan Computational Thinking Siswa SMA dalam Pembelajaran Fisika".

\section{Metode Penelitian}

Metode penelitian yang digunakan adalah SLR (Systematic Literature Review). Metode penelitian ini dilakukan dengan mengidentifikasi, mengkaji, mengevaluasi dan menafsirkan jurnal-jurnal secara sistematis yang pada setiap prosesnya mengikuti langkah-langkah yang telah ditetapkan [14]. Metode SLR disajikan dalam bentuk analisis data berupa deskriptif-kualitatif. Tahapan-tahapan pada penelitian SLR yaitu menetapkan untuk mencari artikel yang berkaitan dengan penggunaan media scratch dan keterampilan computational thinking. Pengumpulan data dilakukan dengan teknik dokumentasi dimana semua artikel yang diperoleh didokumentasikan pada penelitian. Pada penelitian ini terdapat batasan jurnal yang akan di analisis yaitu dimulai dari jurnal tahun 2010-2020, hal ini diperlukan mengingat terbatasnya penelitian yang mengidentifikasi tentang scratch pada pembelajaran fisika. 


\section{Hasil Penelitian dan Pembahasan}

Scratch (http://scratch.mit.edu), dibuat oleh Lifelong Kindergarten Group di MIT Media Laboratory, adalah software yang dapat digunakan oleh pemula dalam pengenalan pemrograman [15], [16]. Sistem scratch dibuat dengan bentuk pemrograman visual di mana pengguna dapat mempelajari tentang sintaks pengkodean dengan cara yang intuitif. Program scratch terdiri dari skrip yang dibuat dengan teknik seret dan lepas dengan blok grafis untuk membuat program [17].

Kelebihan dalam penggunaan media pembelajaran Scratch menurut Resnick antara lain perbedaan (diversity) yaitu mendukung banyak tipe proyek yang berbeda (cerita, permainan, animasi dan simulasi) sehingga siswa dapat tertarik dalam pembuatan proyek dalam scratch dan personalisasi yaitu mempermudah siswa untuk membuat proyek scratch dengan memasukan foto dan video, merekam suara dan membuat grafik [18]. Kelebihan pada scratch ini didukung oleh penelitian bahwa siswa dapat membuat animasi karakter berpindah, melompat, dance dan sing pada media pembelajaran scratch [15], juga penelitian yang menyatakan bahwa scratch dapat dibuat menjadi variasi kreasi yang luas yaitu animasi, simulasi, presentasi, naratif, interactive images, games, dll [19].

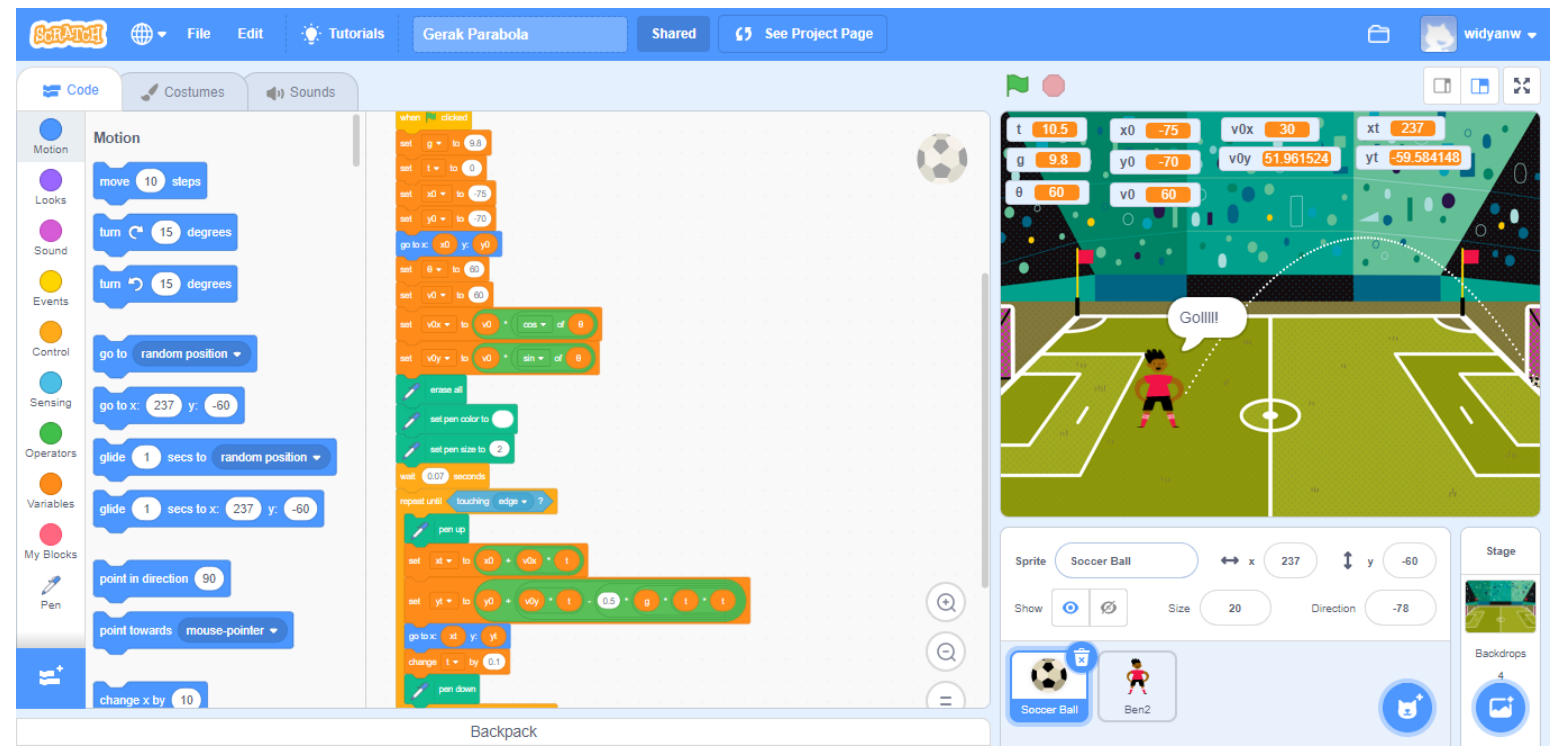

Gambar 1. Tampilan Scratch ${ }^{1}$

Berdasarkan Gambar 1, objek Scratch (sprite) dikonfigurasi menggunakan skrip yang dapat diubah ukuran dan posisinya. Fungsinya dapat disesuaikan dengan serangkaian code yang memberikan action pada sprite berupa motion, looks, sound, events, control, sensing, operators, variables dan my blocks. Kelebihan lain pada penggunaan media pembelajaran scratch adalah action pada sprite ini mudah dan praktis yaitu memiliki bentuk teka-teki grafis sehingga sangat mirip seperti menyusun puzzle. Penyusunan puzzle dalam sebuah program mampu mencegah kesalahan sintaksis sepele yang dapat menyebabkan siswa menjadi kesulitan dalam belajar. Hal ini sejalan dengan penelitian Armoni et al. (2015), Maloney et al. (2010), Tan et al. (2020) bahwa scratch mampu menghilangkan salah satu kendala utama bagi siswa ketika menghadapi pemrograman komputer untuk pertama kali yaitu pengkodean dalam pemrograman yang tidak pernah dipelajari sebelumnya.

Scratch 2.0 merupakan versi terbaru yang menyediakan penggunaan secara online maupun offline [12], [22]. Hal ini dapat mengurangi kesulitan dalam pembelajaran jarak jauh, salah satunya adalah pembelajaran yang mengharuskan siswa belajar online. Kesulitan tersebut dapat diatasi apabila guru mempunyai file scratch yang dapat diinstall oleh siswa, kemudian diberikan penugasan dibantu dengan modul belajar untuk membuat suatu proyek menggunakan scratch.

Scratch didesain untuk mengembangkan kreatifitas, kemampuan berpikir secara sistematis dan belajar secara kelompok yang ketiganya merupakan kemampuan dasar yang harus dimiliki di abad 21 [18]. Hal ini

${ }^{1}$ Dapat diakses pada https://scratch.mit.edu/projects/450026883 
dikarenakan scratch memiliki fasilitas share sehingga memungkinkan siswa untuk membagikan proyek dan mendapatkan umpan balik dan dukungan dari teman sesama pengguna scratch serta dapat belajar dari proyek yang dikerjakan oleh pengguna lainnya. Fitur share pada scratch selain dapat membagikan proyek tetapi juga dapat di embed ke dalam bentuk file PHP maupun HTML [18]. Hasil embed tersebut memungkinkan siswa untuk berkreatifitas membuat web menggunakan bahasa pemrograman PHP maupun HTML yang digabungkan dengan proyek scratch yang telah dibuat secara online.

Disamping itu, scratch memiliki kelemahan dalam penggunaannya. Kelemahan scratch yaitu hasil pembuatan scratch tidak dapat di eksport ke format lain, terbatasnya perintah-perintah untuk merealisasikan algoritma dan hanya tersedia untuk Mac dan Windows (tidak tersedia versi Linux) [23]. Selain itu, kelemahan scratch adalah diperlukan program tambahan pada scratch offline berupa program database dan web server dan diperlukan record untuk mengetahui aktivitas pengguna (user) khususnya siswa saat menggunakan media animasi berbasis scratch [12].

Berdasarkan hasil penelitian di Meerbaum diperoleh bahwa penggunaan media pembelajaran scratch dapat digunakan pada pendidikan formal dan informal [20]. Hal ini didukung oleh media pembelajaran scratch merupakan salah satu alat computational modelling yang dapat digunakan pada sekolah dasar dan sekolah menengah [19]. Selain itu, scratch juga dapat digunakan pada pembelajaran di Universitas [24], [25]. Pada pembelajaran di sekolah maupun universitas, Scratch digunakan untuk membantu pembelajaran pada materi yang abstrak.

Fisika merupakan salah satu pembelajaran yang dianggap memiliki materi yang abstrak dan sulit untuk dipahami [7]. Media scratch telah banyak dikembangkan pada pembelajaran fisika. Media pembelajaran yang dikembangkan harus melalui tahap uji validitas dan uji kelayakan. Berdasarkan hasil uji validitas dan reabilitas beberapa pengembangan media pembelajaran scratch fisika yang dilakukan oleh peneliti terdahulu diperoleh dalam kategori layak untuk diimplementasikan kepada siswa [8], [11], [12], [26]-[31]. Selain itu, telah dikembangkannya modul dan bahan ajar scratch dan diperoleh dalam kategori valid dan layak digunakan oleh guru untuk diimplementasikan kepada siswa [29], [30]. Beberapa materi fisika yang telah dikembangkan oleh peneliti terdahulu menggunakan media scratch yaitu listrik dinamis [8], gerak jatuh bebas dan gerak harmonik sederhana [19], momentum dan impuls [28], [29], vektor [16], optik [16], [26], hukum Oersted [11], dan teori kinetik gas [32].

Pemrograman Scratch memberikan pengalaman kepada siswa dalam membuat media seperti simulasi atau animasi. Siswa akan belajar cara mengidentifikasi, memanipulasi, dan mengintegrasikan media sehingga dapat efektif selama pembelajaran. Scratch melibatkan siswa berpikir sistematis melalui berpikir kritis dan memecahkan masalah dengan ide-ide mereka. Scratch mendorong siswa untuk bekerja secara kolaboratif dengan mendiskusikan skrip simulasi yang dibuat teman mereka [29].

Media pembelajaran scratch mampu meningkatkan hasil belajar siswa. Hal ini sejalan dengan penelitian media pembelajaran scratch mampu meningkatkan hasil belajar siswa pada siklus 1 sebesar 71,4\% kemudian pada siklus 2 meningkat menjadi 94,3\% [33]. Hasil belajar siswa menggunakan media pembelajaran scratch dapat diperoleh dengan menerapkan pola pikir logika yang dapat membuat hal sederhana menjadi kompleks. Hal ini sejalan dengan teori belajar bermakna Ausubel yaitu siswa tidak hanya menerima pembelajaran begitu saja, tetapi siswa menemukan suatu konsep [34], [35]. Teori belajar ini sejalan dengan penggunaan media pembelajaran scratch yang diterapkan dalam pembelajaran yaitu seluruh proses kognitif (berpikir) terjadi selama penggunaan scratch dimulai dari code yang sederhana menjadi suatu action yang mampu membuat suatu proyek dengan konsep-konsep fisika yang diperoleh sehingga menjadikan pembelajaran lebih bermakna. Selain itu, teori Ausubel memandang belajar berpusat pada siswa yang sejalan dengan keterampilan yang akan diukur dalam pembelajaran menggunakan media scratch.

Keterampilan yang dapat ditingkatkan melalui media pembelajaran Scratch yaitu keterampilan berpikir komputasi (computational thinking) [36]. Hal ini didukung oleh penelitian terdahulu yang menyatakan bahwa scratch mampu meningkatkan keterampilan computational thinking sebagai kemampuan untuk terlibat dalam pemecahan masalah menggunakan perangkat komputasi; memanfaatkan sistem komputasi baik online maupun offline; mengumpulkan, mengatur dan menyajikan data secara visual; menggunakan data untuk mencapai abstraksi dan memecahkan masalah; mengembangkan algoritme untuk menggunakan perangkat komputasi secara efisien menggunakan urutan, loop, peristiwa, dan kondisi; dan kemampuan untuk memodifikasi, mengulang, menguji, dan men-debug algoritme tersebut satu per satu secara kolektif [15], [22], [37]-[39]. Aspek keterampilan computational thinking (CT skill) yang dapat ditingkatkan melalui media scratch ditunjukkan pada Tabel 1. 
Tabel 1. Aspek Keterampilan Computational Thinking

\begin{tabular}{|c|c|c|c|c|c|c|c|c|c|c|}
\hline CT Skill & $\begin{array}{c}\text { Barr \& } \\
\text { Stephenson } \\
\text { (2011) }\end{array}$ & $\begin{array}{l}\text { Brenna } \\
\text { n et al. } \\
(2012)\end{array}$ & $\begin{array}{c}\text { Seiter } \\
\& \\
\text { Forema } \\
\text { n (2013) }\end{array}$ & $\begin{array}{l}\text { Curzon } \\
\text { et al., } \\
(2014)\end{array}$ & $\begin{array}{l}\text { Csizma } \\
\text { dia et } \\
\text { al. } \\
(2015)\end{array}$ & $\begin{array}{l}\text { Angeli } \\
\text { et al. } \\
\text { (2016) }\end{array}$ & $\begin{array}{l}\text { Tabesh } \\
\text { (2017) }\end{array}$ & $\begin{array}{l}\text { Chang } \\
\text { et al., } \\
\text { (2018) }\end{array}$ & $\begin{array}{l}\text { Allsop, } \\
\text { (2019) }\end{array}$ & $\begin{array}{l}\text { Yin et } \\
\text { al., } \\
(\mathbf{2 0 2 0})\end{array}$ \\
\hline Abstraction & $\checkmark$ & $\checkmark$ & $\checkmark$ & $\checkmark$ & $\checkmark$ & $\checkmark$ & $\checkmark$ & $\checkmark$ & $\checkmark$ & $\checkmark$ \\
\hline Algorithm & $\checkmark$ & & $\checkmark$ & $\checkmark$ & $\checkmark$ & $\checkmark$ & $\checkmark$ & $\checkmark$ & $\checkmark$ & $\checkmark$ \\
\hline Automation & $\checkmark$ & & & & & & & & $\checkmark$ & \\
\hline Data & $\checkmark$ & $\checkmark$ & $\checkmark$ & & & & & $\checkmark$ & $\checkmark$ & \\
\hline Decomposition & $\checkmark$ & & $\checkmark$ & $\checkmark$ & $\checkmark$ & $\checkmark$ & $\checkmark$ & $\checkmark$ & & $\checkmark$ \\
\hline Evaluation & & & & $\checkmark$ & $\checkmark$ & & & & $\checkmark$ & \\
\hline Event & & $\checkmark$ & & & & & & & $\checkmark$ & \\
\hline $\begin{array}{l}\text { Expressing, } \\
\text { connecting } \quad \& \\
\text { questioning }\end{array}$ & & $\checkmark$ & & & & & & & $\checkmark$ & \\
\hline Generalization & & & & $\checkmark$ & $\checkmark$ & $\checkmark$ & $\checkmark$ & & & $\checkmark$ \\
\hline Parallelism & $\checkmark$ & $\checkmark$ & $\checkmark$ & & & & & $\checkmark$ & $\checkmark$ & \\
\hline Simulation & $\checkmark$ & & & & & & & $\checkmark$ & & \\
\hline $\begin{array}{l}\text { Testing } \quad \& \\
\text { Debugging }\end{array}$ & & $\checkmark$ & & & & & & & $\checkmark$ & \\
\hline
\end{tabular}

Berdasarkan Tabel 1 diperoleh bahwa keterampilan computational thinking memiliki banyak aspek yang dapat diukur dalam pembelajaran dimulai dari tahun 2011 hingga 2020. Aspek keterampilan computational thinking yang dominan adalah abstraction, algorithm, dan decomposition. Keterampilan tersebut merupakan keterampilan dasar yang harus diukur dalam computational thinking. Namun, definisi keterampilan computational thinking pada masing-masing Negara berbeda. Keterampilan computational thinking yang digunakan bergantung pada jenjang kelas yang akan diukur dan tujuan yang mendasarinya [50].

Menurut [49], aspek keterampilan computational thinking yang dapat diukur dalam pembelajaran fisika yaitu abstraction, algorithm, decomposition, dan generalization. Abstraction adalah Keterampilan dalam membuat makna dari data yang ditemukan serta implikasinya. Algorithmic thinking adalah kemampuan untuk berpikir dalam kerangka urutan dan aturan sebagai cara untuk memecahkan masalah. Decomposition adalah cara berpikir tentang artefak dalam kaitannya dengan bagian-bagiannya. Bagian-bagiannya kemudian bisa dipahami, dipecahkan, dikembangkan dan dievaluasi secara terpisah. Pattern recognition/Generalization adalah cara memecahkan masalah baru berdasarkan solusi masalah sebelumnya.

\section{Kesimpulan}

Berdasarkan pemaparan di atas dapat disimpulkan bahwa scratch mampu meningkatkan keterampilan computational thinking siswa karena didesain untuk mengembangkan kreatifitas dengan membuat animasi dan simulasi, kemampuan berpikir secara sistematis, kolaboratif dan dapat merealisasikan algoritma sehingga mampu menerapkan pola pikir logika yang dapat membuat konsep sederhana menjadi kompleks dalam pembelajaran fisika.

\section{Ucapan Terimakasih}

Terima kasih peneliti sampaikan kepada pihak-pihak yang turut mendukung pelaksanaan penelitian ini yaitu sivitas akademika Program Studi Pendidikan Fisika Pascasarjana Universitas Negeri Semarang, dan keluarga peneliti. 


\section{Kepustakaan}

[1] UNESCO, "School closures caused by Coronavirus (Covid-19)," 2020. .

[2] F. N. Arifa, "Tantangan Pelaksanaan Kebijakan Belajar Dari Rumah Dalam Masa Darurat Covid-19," Info Singkat;Kajian Singk. Terhadap Isu Aktual Dan Strateg., vol. XII, no. 7/I, p. 6, 2020.

[3] A. Akhmadi, "Distance Training Evaluation in Pandemy (Evaluasi Pelatihan Jarak Jauh di Masa Pandemi)," J. Diklat Keagamaan, vol. 14, no. 2, pp. 136-144, 2020.

[4] U. Dewi, "Developing Distance Learning Program Using Video Streaming," Proc. Int. Clin. Sci. Publ. Educ. Technol., pp. 913-919, 2016.

[5] N. I. Fata, "Peningkatan Keaktifan Dan Hasil Belajar Siswa Mata Pelajaran Fisika Melalui Pembelajaran Jarak Jauh (Pjj) Kelas X Mipa 2 Semester 2 Tahun 2019/2020 Sma Negeri 1 Rowosari Kabupaten Kendal,” J. Egaliter, vol. 4, no. 7, pp. 13-24, 2020.

[6] A. W. Suryandari and Feli Cianda Adrin Burhendi, "Studi Pendahuluan Karakteristik Pembelajaran Online Fisika Selama Masa Pandemi Covid-19," Pros. Semin. dan Disk. Nas. Pendidik. Dasar 2020, pp. 1-9, 2020.

[7] R. Haryadi and R. Jannah, "Pembelajaran Daring Fisika Pada Siswa Sekolah Menengah Atas ( SMA )," Edumaspul-Jurnal Pendidik., vol. 4, no. 2, pp. 264-268, 2020.

[8] N. Noftiana, M. Nasir, and N. Islami, "Developmental Scratch-Based Online Learning Media in Dynamic Electric Dynamic Topic to Increase Students Concept Understanding in Students Junior High School," J. Phys. Conf. Ser., vol. 1351, no. 1, 2019, doi: 10.1088/1742-6596/1351/1/012014.

[9] P. S. Tambade and B. G. Wagh, "Assessing the Effectiveness of Computer Assisted Instructions in Physics at Undergraduate Level," Eurasian J. Phys. Chem. Educ., vol. 3, no. 2, pp. 127-136, 2011.

[10] P. Karuniakhalida, M. Maimunah, and A. Murni, "Development of ICT-Based Mathematical Media on Linear Program Materials to Improve Motivation Learning Students," J. Educ. Sci., vol. 3, no. 2, p. 195, 2019, doi: 10.31258/jes.3.2.p.195-204.

[11] N. M. Intana, W. Hardyanto, and I. Akhlis, "Pengembangan Multimedia Pembelajaran Fisika Berbasis Scratch pada Pokok Bahasan Hukum Oersted," UPEJ Unnes Phys. Educ. J., vol. 7, no. 2, pp. 1-8, 2018, doi: 10.15294/upej.v7i2.27461.

[12] A. P. Martanti, W. Hardyanto, and A. Sopyan, "Pengembangan Media Animasi Dua Dimensi Berbasis Java Scratch Materi Teori Kinetik Gas untuk Meningkatkan Pemahaman Konsep Siswa SMA," Unnes Phys. Educ. J., vol. 3, no. 3, pp. 77-83, 2014, doi: https://doi.org/10.15294/upej.v2i2.2661.

[13] C. R. Santamaría, C. M. Lora, I. R. Quintana, and M. C. Sellés, "Gamesonomy vs scratch: Two different ways to introduce programming," Proc. 15th Int. Conf. Cogn. Explor. Learn. Digit. Age, CELDA 2018, pp. 216-224, 2018.

[14] J. Aulia, N. D. Permana P, Z. Zarkasih, and T. L. Nova, "Meta-Analisis Pengaruh Penerapan Pendekatan Saintifik Berbantuan Komik terhadap Hasil Belajar IPA Siswa SMP," J. Nat. Sci. Integr., vol. 3, no. 1, p. 70, 2020, doi: 10.24014/jnsi.v3i1.9617.

[15] S. Papadakis, M. Kalogiannakis, N. Zaranis, and V. Orfanakis, "Using Scratch and App Inventor for teaching introductory programming in secondary education. A case study," Int. J. Technol. Enhanc. Learn., vol. 8, no. 34, pp. 217-233, 2016, doi: 10.1504/IJTEL.2016.082317.

[16] C. Monteiro, P. Catarino, A. Soares, and B. Fonseca, "Vector Equation of a Line: a Scratch Application," EDULEARN19 Proc., vol. 1, no. July, pp. 3911-3914, 2019, doi: 10.21125/edulearn.2019.1003.

[17] J. Maloney, M. Resnick, N. Rusk, B. Silverman, and E. Eastmond, "The scratch programming language and environment," ACM Trans. Comput. Educ., vol. 10, no. 4, pp. 1-15, 2010, doi: 10.1145/1868358.1868363.

[18] S. N. K. Amrullah, "Pengembangan Media Pembelajaran Online Berbasis Scratch pada Pokok Bahasan Getaran," Universitas Negeri Semarang, 2015.

[19] V. Lopez and M. I. Hernandez, "Scratch as a computational modelling tool for teaching physics," Phys. Educ., vol. 50, no. 3, pp. 310-316, 2015, doi: 10.1088/0031-9120/50/3/310.

[20] M. Armoni, O. Meerbaum-Salant, and M. Ben-Ari, "From scratch to 'Real' programming," ACM Trans. Comput. Educ., vol. 14, no. 4, 2015, doi: 10.1145/2677087.

[21] W.-L. Tan, M. A. Samsudin, M. E. Ismail, and N. J. Ahmad, "Gender Differences in Students' Achievements in Learning Concepts of Electricity Via Steam Integrated Approach Utilizing Scratch," Probl. Educ. 21st Century, vol. 78 , no. 3, pp. 423-448, 2020, doi: $10.33225 /$ pec/20.78.423.

[22] P. Plaza, E. Sancristobal, G. Carro, M. Castro, and M. Blazquez, "Scratch day to introduce robotics," IEEE Glob. Eng. Educ. Conf. EDUCON, vol. 2018-April, pp. 208-216, 2018, doi: 10.1109/EDUCON.2018.8363230.

[23] E. D. Naibaho, "Pengembangan Media Pembelajaran Scratch pada Mata Pelajaran IPA Kelas V Materi Kerangka Manusia," Universitas Sanata Dharma, 2019.

[24] J. A. Martínéz-Valdés, J. Angél Vélazquéz-Iturbidé, and R. Hijon-Néira, "A (relatively) unsatisfactory experience of use of Scratch in CS1," ACM Int. Conf. Proceeding Ser., vol. Part F1322, pp. 1-7, 2017, doi: $10.1145 / 3144826.3145356$.

[25] B. J. Johnson and A. H. Louw, "Building a research culture from scratch at a university of technology," 
Mediterr. J. Soc. Sci., vol. 5, no. 1, pp. 151-164, 2014, doi: 10.5901/mjss.2014.v5n1p151.

[26] L. P. Arfiansyah, I. Akhlis, and Susilo, "Pengembangan Media Pembelajaran Berbasis Scratch pada Pokok Bahasan Alat Optik," UPEJ Unnes Phys. Educ. J., vol. 8, no. 1, pp. 66-74, 2019, doi: 10.15294/upej.v8i1.29515.

[27] J. E. Prayitno, "Pengembangan Media Animasi Interaktif Berbasis Scratch untuk Materi Lensa," Universitas Negeri Semarang, Semarang, 2017.

[28] V. Serevina, H. and Nasbey, and W. Andriana, "The Development of a Learning Material Using The Scratch Programming Language to Helping Student Leaning Momentum and Impulse Subject in Senior High School," Proc. Int. Conf. Technol. Soc. Sci., pp. 2-7, 2017.

[29] A. Rusilowati, B. Subali, M. P. Aji, and R. A. Negoro, "Development of teaching materials for momentum assisted by scratch: Building the pre-service teacher's skills for 21 st century and industry revolution," J. Phys. Conf. Ser., vol. 1567, no. 2, 2020, doi: 10.1088/1742-6596/1567/2/022010.

[30] I. Khasyyatillah and K. Osman, "The Development of CT-S Learning Module on The Linear Motion Topic to Promote Computational Thinking Thinking," J. Educ. Sci., vol. 3, no. 3, p. 270, 2019, doi: 10.31258/jes.3.3.p.270-280.

[31] A. Afandy, W. Hardyanto, and I. Akhlis, "Simulation of electron motion in electric and magnetic fields using scratch," vol. 2, no. 5, pp. 177-182.

[32] A. P. Martanti, "Pengembangan Media Animasi Dua Dimensi Berbasis Java Scratch Materi Teori Kinetik Gas Untuk Meningkatkan Pemahaman Konsep Siswa Sma," UPEJ Unnes Phys. Educ. J., vol. 2, no. 2, 2013, doi: 10.15294/upej.v2i2.2661.

[33] L. Permatasari, R. A. Yuana, and D. Maryono, "Implementation of Scratch Application to Improve Learning Outcomes and Student Motivation on Basic Programming Subjects," IJIE (Indonesian J. Informatics Educ., vol. 2, no. 2, p. 95, 2018, doi: 10.20961/ijie.v2i2.15206.

[34] C. I. Yogihati, "Peningkatan Kualitas Pembelajaran Fisika Umum Melalui Pembelajaran Bermakna Dengan Menggunakan Peta Konsep," J. Pendidik. Fis. Indones., vol. 6, no. 2, pp. 104-107, 2010, doi: 10.15294/jpfi.v6i2.1121.

[35] H. Saputra, "Peningkatan Daya Serap Siswa dalam Pembelajaran Matematika dengan Penerapan Teori Belajar Bermakna David Ausubel," J. Penelit. Pendidik. MIPA, vol. 1, no. 1, pp. 21-26, 2016.

[36] A. Fidai, M. M. Capraro, and R. M. Capraro, "Scratch'-ing computational thinking with Arduino: A metaanalysis," Think. Ski. Creat., vol. 38, no. July, p. 100726, 2020, doi: 10.1016/j.tsc.2020.100726.

[37] C. S. Lee and B. Jiang, "Assessment of computational thinking (CT) in scratch fractal projects: Towards CTHCI Scaffolds for Analogical-fractal Thinking," CSEDU 2019 - Proc. 11th Int. Conf. Comput. Support. Educ., vol. 1, no. Csedu, pp. 192-199, 2019, doi: 10.5220/0007755401920199.

[38] M. J. Marcelino, T. Pessoa, C. Vieira, T. Salvador, and A. J. Mendes, "Learning Computational Thinking and scratch at distance," Comput. Human Behav., vol. 80, pp. 470-477, 2018, doi: 10.1016/j.chb.2017.09.025.

[39] I. N. Serbec, S. Cerar, and A. Zerovnik, "Developing Computational Thinking through Games in Scratch," Proc. 20th Asian Technol. Conf. Math., no. June, pp. 73-87, 2015.

[40] V. Barr and C. Stephenson, "Bringing computational thinking to K-12: What is involved and what is the role of the computer science education community?," ACM Inroads, vol. 2, no. 1, pp. 48-54, 2011, doi: $10.1145 / 1929887.1929905$.

[41] K. Brennan, M. Resnick, and MIT Media Lab, "New frameworks for studying and assessing the development of computational thinking," in AERA, 2012, pp. 1-25, doi: 10.1007/978-3-319-64051-8_9.

[42] L. Seiter and B. Foreman, "Modeling the learning progressions of computational thinking of primary grade students," ICER 2013 - Proc. 2013 ACM Conf. Int. Comput. Educ. Res., pp. 59-66, 2013, doi: 10.1145/2493394.2493403.

[43] P. Curzon, M. Dorling, T. Ng, C. Selby, and J. Woollard, "Developing computational thinking in the classroom: a framework," Comput. Sch., no. June, pp. 1-6, 2014.

[44] A. Csizmadia et al., "Computational thinking A guide for teachers," p. 18, 2015.

[45] C. Angeli et al., "International Forum of Educational Technology \& Society A K-6 Computational Thinking Curriculum Framework: Implications for Teacher Knowledge,” Source J. Educ. Technol. Soc., vol. 19, no. 3, pp. 47-57, 2016.

[46] Y. Tabesh, "Computational thinking: A 21st century skill," Olympiads in Informatics, vol. 11, no. Special Issue, pp. 65-70, 2017, doi: 10.15388/ioi.2017.special.10.

[47] Z. Chang, Y. Sun, T. Y. Wu, and M. Guizani, "Scratch Analysis Tool(SAT): A Modern Scratch Project Analysis Tool based on ANTLR to Assess Computational Thinking Skills," 2018 14th Int. Wirel. Commun. Mob. Comput. Conf. IWCMC 2018, pp. 950-955, 2018, doi: 10.1109/IWCMC.2018.8450296.

[48] Y. Allsop, “Assessing computational thinking process using a multiple evaluation approach,” Int. J. ChildComputer Interact., vol. 19, pp. 30-55, 2019, doi: 10.1016/j.ijcci.2018.10.004.

[49] Y. Yin, R. Hadad, X. Tang, and Q. Lin, "Correction to: Improving and Assessing Computational Thinking in Maker Activities: the Integration with Physics and Engineering Learning (Journal of Science Education and 
Technology, (2020), 29, 2, (189-214), 10.1007/s10956-019-09794-8)," J. Sci. Educ. Technol., vol. 29, no. 2, p. 215, 2020, doi: 10.1007/s10956-020-09822-y.

[50] L. C. Zhang and J. Nouri, "A systematic review of learning computational thinking through Scratch in K-9," Comput. Educ., vol. 141, no. June, p. 103607, 2019, doi: 10.1016/j.compedu.2019.103607. 